\title{
Utilization of Information Processing Theory to Identify Students' Thinking Interference of Global Type in Solving Permutation Problems
}

\author{
$1^{\text {st }}$ Sukoriyanto \\ Department of Mathematics \\ Universitas Negeri Malang \\ Malang, Indonesia \\ sukoriyanto.fmipa@um.ac.id
}

\begin{abstract}
This study aims to describe the students' thinking interference of global type in solving permutation problem based on information processing theory. The subjects were 16 students of the Mathematics Department, Universitas Negeri Malang. The results showed that $50 \%$ of student's experience global interference when solving combination problems. Interference experienced by students occurs when students call information in long-term memory to be used to solve problems in short-term memory.
\end{abstract}

Keywords - Thinking interference, Information processing theory, Combination.

\section{INTRODUCTION}

Thinking is the process of obtaining information, processing information, store information, and recall information controlled by the brain [1]. According to Prayitno, thinking is a new mental representation process that is formed through the transformation of information that interacts with complex mental attributes. Such mental attributes are the abstraction, judgment, imagination, problem-solving, and logic [2]. Someone thinks when faced with a problem that he deems challenging and requires a solution. It shows that thinking is a mental activity experienced by a person when faced with a problem to be solved. One's thinking process can be seen through the work or verbal expression.

Thinking is a sequence of processes from when information goes in, processing to form a thinking scheme that is a dynamic process that can be described by processor path. This discourse enclosed that in the thinking of information processing occurs. This is in the opinion of Rehalat showed that in information processing there is an interaction between external conditions and the internal conditions of the individual. External conditions are the stimuli of the environment that affect the individual in the learning process. While the internal condition is the state in the individual that is required to achieve learning outcomes and cognitive processes that occur in individuals [3].

Information processing theory is a related cognitive theory of learning that describes the processing, storage, and recall of knowledge from the brain [1]. Meanwhile, Panjaitan mentioned that information processing involves receiving information and organizing it with what has been known before, storing information, and call back the information when needed [4]. This theory explains how one obtains some information and can be remembered for a long time. Information is processed and stored in three stages, namely sensory registers, short-term memory, and long-term memory [1].

The first stage of the memory system encountered by incoming information is the sensory register. The visual recording receives a significant amount of information from the senses and stores it in an immediate time [1]. If there is no process for the information stored in the sensing register, then quickly the information will be lost. Information processing in this first stage is essential because it becomes a requirement to be able to process information in the next stage, so the attention of students to the new information received this becomes very necessary [4].

A person's interpretation of stimuli is said to be perceived. Perceptions of indirect stimulus such as stimulus reception, because perception is influenced by mental status, experience, knowledge, motivation, and many other factors [1]. Information that a person perceives and gets attention will be transferred to the second component of the memory system, i.e., short-term memory.

Information perceived and received attention from students is transferred to the second component of the memory system, i.e., short-term memory or working memory). Short-term memory is a limited information storage system in just a few seconds [1]. Short-term memory relates to what one is thinking of when receiving stimuli from the environment. Information that goes into short-term memory gradually disappears when the information is no longer needed [4]. If the information in this short-term memory continues to be used, then over time the information goes to the next information store, which is the long-term memory. For that one way to store information in short-term memory is to think about that information or reveal it over and over again.

Long-term memory is part of a memory system where information is stored for long periods [1]. Meanwhile, Panjaitan (2013) showed that long-term memory is a relatively permanent storage memory, which can store information even though the information is not needed anymore [4]. Information stored in long-term memory is organized into a particular form of knowledge structure or so-called schema. Schema groups information elements according to how the information will be used, so the schema facilitates access to information in the future when it will be used.

When students are given problems related to permutations or combinations, they are viewed as external stimuli. Problems related to permutations or combinations that students face into the sensory register. If the problem 
does not get the attention of the student, then the problem will be forgotten by the student. If the problem gets the attention of the student, then it will be transferred to the second component of the system memory, which is working memory or short-term memory. In the second component of the memory system, students in solving permutation problems or faced combinations require schema-shaped information stored in long-term memory with retrieval of schema-shaped information stored in long-term memory. When retrieving schema-shaped information stored in longterm memory, sometimes when students face permutation problems but the schema used to complete is a combination schema or vice versa. Such an event is called interference.

Students of Mathematics Department Universitas Negeri Malang still have difficulties when solving problems related to permutations and combinations [5]. At the moment students are given problems related to a combination that still exists using the concept of permutation [6]. According to Sukoriyanto et al. (2016) the student is experiencing global interference [5].

Based on students' difficulties in working on permutation and combination problems so that students experience global interference and using the information processing theory framework, this study will describe the interference of thinking of global type students in solving permutation problem based on information processing theory.

\section{METHODS}

The subjects in this study were 16 students consisting of 10 female students and six male students. Subsequently, subjects are asked to work on issues related to permutations. If the permutation problem given is done using a combination, then it is chosen to be the subject of the study. A student from the student group solved the permutation problem by using a combination to disclose global type interference based on information processing theory.

The problem of permutation given to the students is as follows "In a study room there are four different titles of books A, B, C and D. There are four books for each title. In how many different ways can they are arranged in a rack? "

\section{RESULTS AND DISCUSSION}

The subjects chosen to describe the global type of interference based on information processing theory were given prior $\mathrm{S} 1$. Based on the results of the interview the subject $S$ puts his full attention on facing the permutation problem. Attention $\mathrm{S} 1$ to the problems encountered is marked by the effort of $\mathrm{S} 1$ to solve the problems faced.

Because $\mathrm{S} 1$ is concerned about the problems faced, the problems associated with the permutation faced by the $\mathrm{S} 1$ move from the recording of the senses to the working memory or short-term memory. S1 requires information in long-term memory to solve problems encountered in shortterm memory, but S1 experience interference in solving problems encountered. S1 has an error in solving the permutation problem encountered due to the occurrence of withdrawal barrier information related to the permutation caused by information related to the pulled permutation obstructed by information related to the combination
Interference experienced by $\mathrm{S} 1$ occurs because based on information received $\mathrm{S} 1$ is a book that must be laid out is 16 books. Each title consists of 4 books. A book titled the same is not distinguished. However, S1 considered that the books should be arranged in 4 bookshelves. Regardless of the other information (information that is forgotten) is a book that is organized consisting of 4 titles. Based on the information received by the $S 1$ is to arrange 16 books in 4 place slots and books titled the same is not distinguished in solving the problem S1 looked at (information that is called from longterm memory). It is a problem that does not need to note the order. Because there is no need to pay attention to the sequence, the problem faced by $\mathrm{S} 1$ is interpreted (information called from long-term memory) as a combination problem and solved using 16C4.

From the problems identified by $\mathrm{S} 1$, the relationship that has been recognized by the $S 1$, the strategy recognized by $\mathrm{S} 1$ and the count done by S1 obtained the description that if there are 4 titles of books and each title consists of 4 books and regardless of the given problem, S1 looked at the book the book should be arranged in 4 bookshelves. By recognizing the condition then S1 looked at each shelf containing four books. Regardless of the problem, S1 considers that if each shelf contains four books and the first shelf contains four books with the title A, the second shelf contains four books with the title B, the third shelf contains four books with title $\mathrm{C}$, and the fourth shelf contains four books with title D. Moreover, S1 sees a book entitled as not being distinguished as an event that does not need to pay attention to sequence. Due to the arrangement of the book on the first rack, the second rack, the 3rd rack and the 4th rack by $\mathrm{S} 1$ are considered unnecessary, so S1 determines that there are four place slots in the book arrangement and do not need to pay attention to the sequence. Because of the number of books that have to be arranged, there are 16 books, and there are four place slots and do not need to pay attention to the sequence so S1 determines that the problems encountered can be solved by using a combination with the $16 \mathrm{C} 4$ formula. The result of the S1 work in solving the permutation problem solved using the combination can be seen in Fig. 1 below.

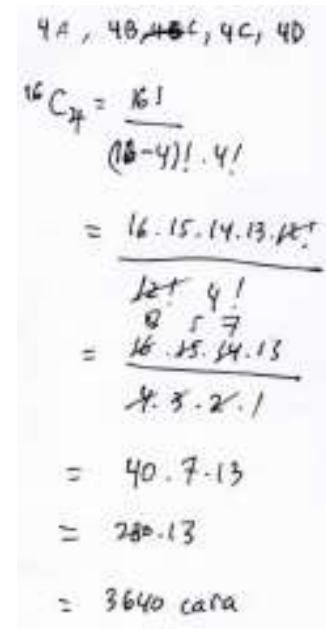

Fig. 1. Results of Work S1 
The answer produced by $\mathrm{S} 1$ in solving permutation problems using a combination is a decision taken. If information related to the decision made by the $\mathrm{S} 1$ in answering the problems encountered is not required anymore, then the information will gradually disappear. However, if the information related to the decision made by the $\mathrm{S} 1$ in answering the problems encountered is often used then through the process of rehearsal and coding, the decision made by $\mathrm{S} 1$ in answering permutation problem using a combination sent to long-term memory to be stored and become new knowledge possessed by $\mathrm{S} 1$. Based on the above exposure, the occurrence of thinking interference from $\mathrm{S} 1$ based on information processing theory can be seen in Fig. 2 below.

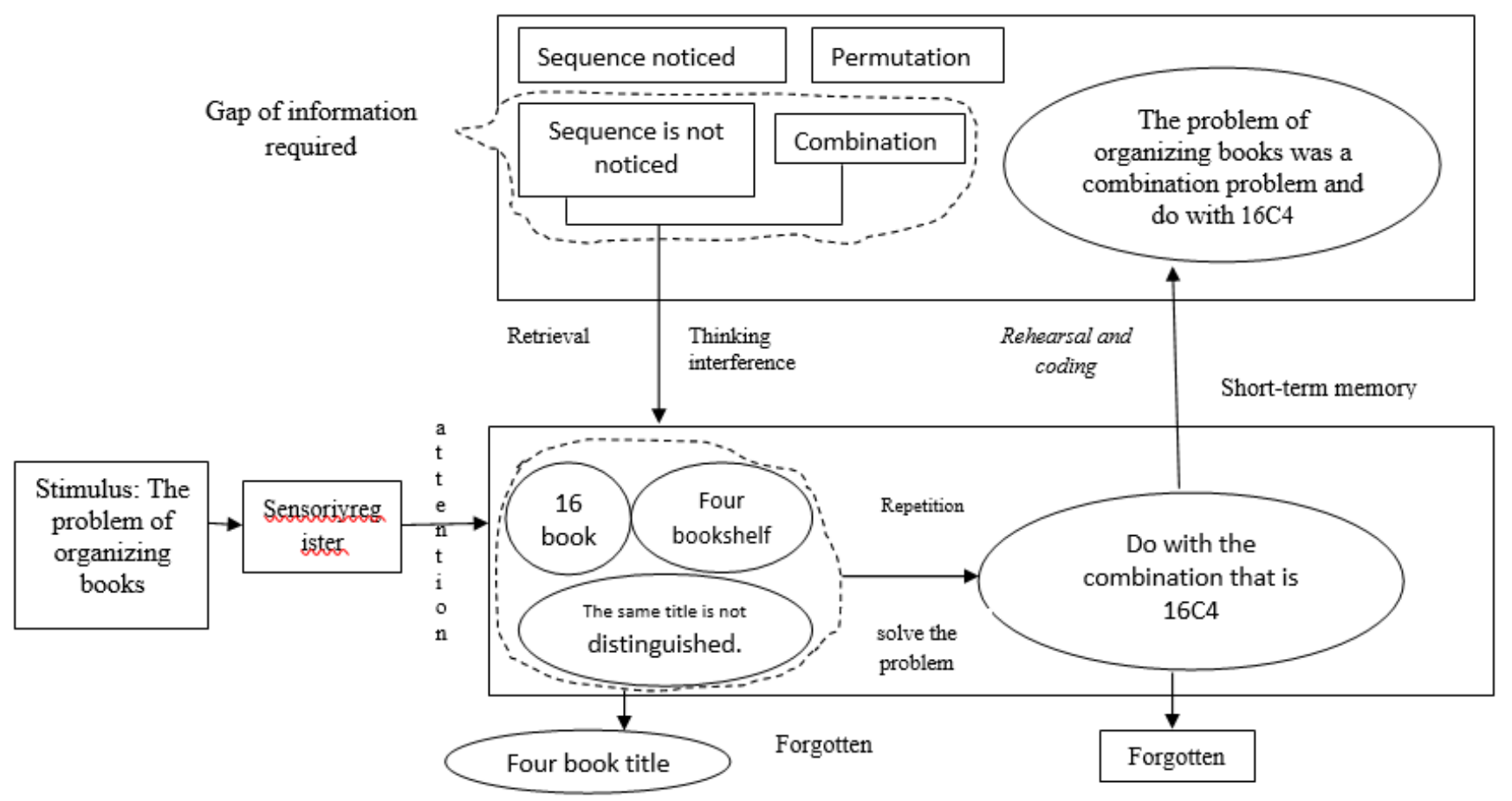

Fig. 2 The occurrence of Thinking Interference S1 Based on Information Processing Theory

The occurrence of interference thinking $\mathrm{S} 1$ due to $\mathrm{S} 1$ forgot the information associated with the book is arranged consists of 4 different titles of books. Moreover, if it set the four titles of different books then must pay attention to the sequence. By forgetting the information about the book is arranged consists of 4 different titles, the information owned by $\mathrm{S} 1$ in solving the problems encountered is there are 16 books, arranged in 4 bookshelves and books entitled the same is not distinguished. Based on the information then S1 interpret in the book arrangement does not need to pay attention to the order and solved by using a combination. Using information processing theory can be identified as the cause of thinking interference from $\mathrm{S} 1$, but not able to see the structure of thinking $\mathrm{S} 1$ at the time of interference thinking.

In this case, the $\mathrm{S} 1$ thinking strap considers the permutation problem encountered solved by using a combination. So it gets an unsuitable answer (wrong). The incidence experienced by $\mathrm{S} 1$ in dealing with permutation problems but resolved by using a combination is called global interference.

\section{CONCLUSION}

Based on the information processing theory, it was investigated that the interference of thinking of the global type of student in solving permutation problem happened because the student forgot important information related to the order notes. The forgotten sequence of intertwined information will impact to the information on the long-term memory which related to the combination. So the permutation problem encountered is solved by a combination.

In permutation and combination learning activities, lecturers should always emphasize the students always to remember all the information needed in solving the problem so as not to experience interference thinking.

\section{REFERENCES}

[1] Slavin, R.E., Educational Psychology Theory and Practice, Eighth Edition, Washington DC: Pearson, 2006.

[2] Prayitno, A., Proses Berpikir Reflektif Mahasiswa dalam Menyelesaikan Masalah Matematika, Unpublished Disertation, Malang : Universitas Negeri Malang, 2015.

[3] Reheat, A., "Model Pembelajaran Pemrosesan Informasi," Jurnal Pendidikan Ilmu Sosial, vol. 23(2), pp 1 - 10, 2014.

[4] Panjaitan, B., "Proses Kognitif Siswa Dalam Pemecahan Masalah Matematika,” Jurnal Ilmu Pendidikan, vol. 19(1), pp. 17-25, 2013. 
[5] Sukoriyanto, Nusantara, T., Subanji and Candra, T.D., "Students' Errors in Solving the Permutation and Combination Problems Based on Problem Solving Steps of Polya," International Education Studies, vol. 9(2), pp. 11-16, 2016.

[6] Sukoriyanto, Nusantara, T., Subanji and Candra, T.D., "Students' Thinking Interference of Real Global Type in Solving Permutation and Combination Problems," IOSR Journal of Research \& Method in Education, vol. 6(5), pp. 47-50, 2016. 